\title{
AQUÉM DA LINGUAGEM: O INDIZÍVEL NA POESIA DE PAUL CELAN
}

\author{
Mariana Camilo de Oliveira
}

Mestre em Letras: Teoria da Literatura - UFMG

\begin{abstract}
RESUMO
A aporia entre trauma e representação, presente na poesia celaniana, é amiúde contraposta ao "dictum" adorniano da impossibilidade da lírica após Auschwitz. No presente trabalho, pretende-se discorrer sobre tal aporia, a partir do legado de Celan. Vislumbra-se a saída do impasse através de uma ética da representação, que não repete o trauma obscenamente ou se cala, mas incorpora o silêncio. Assim, a poética de Celan cita o ocorrido, evocando-o metonimicamente, à maneira da madeleine proustiana. Deparamo-nos com uma lírica indicial que, como cicatriz ou ruína, é contígua à memória.
\end{abstract}

\section{PALAVRAS-CHAVE}

Poesia, Paul Celan, indizível, catástrofe

Que tempos são estes, em que uma conversa sobre árvores chega a ser uma falta Pois implica em silenciar sobre tantos crimes? ${ }^{1}$

Uma folha, sem árvores, para Bertolt Brecht: que tempos são estes, em que uma conversa é quase um crime pois tanto dizer comprime ${ }^{2}$

Que tempos são estes, em que quaisquer intentos de articulação através da linguagem parecem um crime?, diz o poeta (justamente aquele que teve que encontrar outro modo de

\footnotetext{
${ }^{1}$ BRECHT. Poemas e canções, p. 91 . Texto adaptado.

${ }^{2}$ CELAN. Die Gedichte: Kommentierte Gesamtausgabe, p. 333. (tradução nossa)
} 
articulação). "Que voz crítica pode sobreviver ao convívio aturado com esta poesia?", 3 indaga João Barrento. Que pode esta voz crítica dizer, diante desta poética do silêncio e do negativo, sem recair ela mesma no palavreado banal, "bunte Gerede" [tagarelice colorida], "Sprachgestöber" [turbilhão de linguagem] ou, ainda, (benjaminianamente) no "documento de barbárie"; sem a pretensão oculta de tornar Auschwitz (e a poesia após Auschwitz) digerível, representável e assimilável? Ou, também, sem recair no relativismo do sem sentido, em que qualquer ficção é válida? Com tais impasses sem soluções satisfatórias deve conviver o leitor da lírica celaniana. Esta, cuja leitura é perigosa experiência, travessia arriscada, posto que se dá no território deslizante entre a linguagem e os acontecimentos traumáticos.

Nesses tempos sombrios e em território aporético emerge a obra do poeta Paul Celan pseudônimo anagramático e literário de Paul Antschel, nascido na cidade romena de Czernowitz, Bucovina (hoje pertencente à Ucrânia), em 1920, filho de judeus falantes de alemão, cujos pais foram deportados para um campo de extermínio em Michailowka, em 1942, e ali morreram. Celan permaneceu durante 18 meses em campo de trabalho. Estabeleceu-se em Paris, em 1948, onde passou a lecionar e a traduzir. Paul Celan suicidou-se em Paris, aos 20 de abril de 1970, saltando da ponte Mirabeau ao rio Sena. O poeta consagrou-se entre os maiores da literatura alemã do século 20 - especialmente após o conhecido poema "Todesfuge" ["Fuga da morte"], de recepção controvertida, ${ }^{4}$ no qual evoca o horror da Shoah, levando muitos a questionarem o suposto veredicto adorniano: "A crítica cultural encontra-se diante do último estágio da dialética entre cultura e barbárie: escrever um poema após Auschwitz é um ato bárbaro, e isso corrói até mesmo o conhecimento de por que se tornou impossível escrever poemas."

Tal afirmação acerca da impossibilidade da poesia e da crítica após Auschwitz e a obra de Paul Celan são frequente e exaustivamente evocadas como antagônicas. As catástrofes do

\footnotetext{
${ }^{3}$ BARRENTO. Paul Celan: o Verbo e a Morte, p. XXIX.

${ }^{4}$ O poema obteve problemática recepção no espaço germanófono nos anos 1950 e 1960 - que consistiu, por parte da imprensa alemã daquele período, em considerar, como poesia após Auschwitz, uma barbárie, por ser uma espécie de embelezamento dos campos de concentração, do grito de morte do prisioneiro; que o poema seria uma continuação dos campos, construído com a mesma precisão e refinamento que os mesmos. Isso tornaria Celan também numa espécie de "mestre" celebrado, o mesmo trazido à tona no poema. Celan dá diversas respostas, poéticas e políticas, ao proibir a publicação do poema em algumas antologias, não o ler mais em público, ao negar o princípio da composição musical em fuga - tema e contratema. E responde também através de sua poesia. Trata-se de um poema que, é claro, difere de um relato testemunhal, mas é atípico em sua explicitação, um corpo estranho no corpus de poemas de Celan.
}

${ }^{5}$ ADORNO. Crítica cultural e sociedade, p. 26. 
século 20, em especial, para nosso propósito, a Shoah, é uma espécie de paradigma do "real", que escapa à malha simbólica. Esboça-se, assim, o problema que nos mobiliza.

A primeira indagação a se fazer presente em nossos esforços consiste no problema da representação-apresentação do evento traumático, considerado indizível. Tal representação e a poesia são, em Celan, possíveis após Auschwitz - sem tornar novamente possível o "belo" e o rapidamente assimilável -, e não sem preço. Celan faz uso de procedimentos poéticos para, nas palavras de Adorno, "exprimir o horror através do silêncio"; 6 estes, ao longo da obra, de maneira cada vez mais silenciosa, lacunar, fragmentária e vazia, em radical experiência com a língua.

Este "exprimir através do silêncio" mostra que há, na lírica celaniana, uma "ética da representação", sempre atrelada à sua técnica, incorporando o silêncio na sua poesia de maneira a não produzir um excesso de aisthesis ${ }^{7}$ em sua apresentação do real, seguindo as reflexões de Márcio Seligmann-Silva, que "cega" e inviabiliza a reflexão sobre a mesma.

A noção mesma de indizível ganha nova acepção após a Shoah - aquela passa a remeter inevitavelmente a esta, sendo não apenas o inefável, mas também o indizível metonímico dos "dentes" e dos "cabelos". ${ }^{8}$ Do mesmo modo, o conceito de sublime ganha novas dimensões e articulações, como demonstra Seligmann-Silva. ${ }^{9}$

A plausibilidade da conciliação entre arte e dor, para além de se demonstrarem não excludentes, emerge de um modo particular após a Segunda Guerra Mundial e, assim, "arte da dor" ou "arte do corpo" sinalizam um novo olhar sobre o "real". Valer-se do corpo e seus limites como suporte da arte - seja através de cortes, secreções - decorre da violência da técnica e a desafia. Seligmann-Silva menciona, para referir-se a esta chamada arte abjeta, as performances de autodestruição, extensões da pele, body art, suspensões do corpo, entre outros que, como diz, desconstroem a representação. ${ }^{10}$ Em alguns casos, afirma, a superestetização culmina na antiestética - "percepção (aisthesis) em demasia tranforma-se em impossibilidade de percepção" -, a visão do "real" produz uma espécie de "queimadura"; um

\footnotetext{
${ }^{6}$ ADORNO. Teoria estética, p. 354.

${ }^{7}$ SELIGMANN-SILVA. O local da diferença, p. 55.

${ }^{8}$ Pode-se dizer que as palavras, em Celan, são, de certo modo, "dentes" e "cabelos". As palavras utilizadas pela testemunha - também a jurídica - são partes de uma realidade, indícios de um crime. Seligmann-Silva observa, em nota, que a arte e a literatura com forte teor testemunhal têm as quatro características do índice definidas por Peirce: conexão física, singularidade, designação (aponta, é um gesto) e atestação (atesta, dá testemunho.) (SELIGMANN-SILVA. O local da diferença, p. 43.)

${ }^{9}$ SELIGMANN-SILVA. O local da diferença, p. 31-44.

${ }^{10}$ SELIGMANN-SILVA. O local da diferença, p. 51-52.
} 
"corte" na película do "real" que dissolve fronteiras, característico da pós-modernidade. ${ }^{11}$ Em torno desse argumento, Celan emerge: ao contrário do cegamento produzido pelo excesso de percepção, o poeta fomenta a reflexão sobre a ética (da representação), que supõe um limite e respeito ao outro, menciona, entre o sublime e o abjeto. O indizível em Celan não está, enfim, no âmbito do sublime que eleva, tampouco na exibição do cadáver que impede a percepção.

Gagnebin constata que a discussão sobre uma estética do irrepresentável, do indizível ou mesmo do sublime, está muito mais presente nas pesquisas atuais sobre a literatura dos campos de concentração. No entanto, afirma, o sublime não mais designa o inefável que ultrapassa a compreensão humana, mas as cinzas, os cabelos sem cabeça, os dentes arrancados, sangue e excrementos; sublime de lama e cuspe, por baixo, sem enlevo nem gozo. $^{12}$

Diante da lírica celaniana pode-se formular a noção de testemunho metonímico. Este difere da exposição banal do horror, bem como de um contramodelo de testemunho mimético (imitativo), que teria uma pretensão totalizante. O testemunho metonímico é um índice, e assim é, ele também, uma espécie de "estilhaço" resultante da explosão da catástrofe. São os cabelos (os de "ouro de Margarete" e de "cinzas de Sulamita", de "Todesfuge"), bem como no poema "MANDORLA": "Madeixa de Judeu, és imortal" e "Madeixa de homem, és imortal"; e dentes, "Schreibzähnen" [“dentes de escrita"]:

Falar com os becos sem saída

ali defronte,

da sua

expatriada

significação - :

mastigar

este pão, com

dentes de escrita ${ }^{13}$

A palavra-objeto, indicial ou indexal, recorte da catástrofe, é também um "estilhaço", como "Wolfsbohne" [grão-de-lobo]: título de um poema de Celan não publicado em vida. "Wolfsbohne" é o nome de uma planta - e de pouco nos serve a busca exaustiva de referências sobre ela -, é uma palavra utilizada pela mãe, que, metonimicamente, a cita. No poema, "Wolfsbohne" e "Lupine" [lupino] funcionam como "palavras-estilhaço".

\footnotetext{
${ }^{11}$ SELIGMANN-SILVA. O local da diferença, p. 55.

${ }^{12}$ GAGNEBIN. Após Auschwitz, p. 79.

${ }^{13}$ CELAN. Sete rosas mais tarde: antologia poética, p. 169.
} 
Lá longe, em Michailowka, na

Ucrânia, onde

eles me mataram pai e mãe: que

floria aí, que

floresce aí? Que

flor, mãe

te fazia doer aí

com o seu nome,

mãe, a ti,

que dizias grão-de-lobo, e não

lupino?

Ontem

veio um deles e

matou-te

outra vez no

meu poema. ${ }^{14}$

A palavra é, ela mesma, um cadáver que deve ser lavado e poesia de Celan é também uma forma de lavar o cadáver-palavra, como no poema:

Uma palavra - bem sabes:

um cadáver.

Vamos lavá-lo,

vamos penteá-lo,

vamos voltar-lhe os olhos

para o céu. ${ }^{15}$

Encontramo-nos no âmbito do indizível - não aquele que está além da linguagem (da "mística inefável” ou do "sublime espiritualista"), mas justamente, em sua materialidade, aquilo que está aquém da linguagem.

Vemo-nos, também, às voltas com a leitura sob uma perspectiva da poesia hermética. Trata-se de uma dicotomia corrente na fortuna crítica de Celan: entre o hermetismo e a dialogia; além desta (talvez um pouco mais démodé), o impasse entre poesia engajada, de potencial político, e a da autorreferencialidade, do puro experimento da forma. Pode-se compreender a poesia hermética, cifrada ou críptica como um esforço de afastamento do "bunte Gerede", de modo que ela se fecha, de maneira opaca; ao mesmo tempo, contudo, é dialógica, aberta, que almeja o encontro, em busca de um "tu" ou de uma "realidade", não endereçada, mas sempre endereçável.

Para abordar problema referente aos efeitos da escritura, formulei três hipóteses de trabalho: a primeira via, da possibilidade da representação, a segunda, da impossibilidade, que escapa irrefreavelmente à linguagem. Ambas encontram seus representantes na obra de Celan.

\footnotetext{
${ }^{14}$ CELAN. A morte é uma flor: poemas do espólio, p. 28-35.

${ }^{15}$ CELAN. Sete rosas mais tarde: antologia poética, p. 59.
} 
Ambas, contudo, parecem ser contestáveis pela mesma obra. A primeira, pela aposta na função comunicativa da linguagem, o que é imediatamente desmantelado pelo poeta - pela crença na abertura e por tornar Auschwitz algo digerível. A segunda, pela solução "fácil" do hermetismo, de um passado que tão somente impede o fluxo da narrativa, relativamente obscurantista e imobilista.

E a terceira via, de uma possibilidade (através dos procedimentos poéticos que introduzem o silêncio), porém não sem preço. Percebemos que a escrita - esta escritura da dor - se dá em contiguidade com uma vida também dolorosa. A dor da vida e a dor do texto mostram-se através desta poesia perpassada pelo evento traumático, bem como da visão abismal e melancólica do objeto perdido e reencontrado. Um reencontro que se dá na língua materna e dos assassinos (Muttersprache-Mördersprache, a mesma língua ensinada pela mãe e língua dos assassinos da mãe), a única língua passível de ser território para o reencontro. Esta língua da poesia, de Hölderlin e da tradição, mas também da esfera do plágio, do "roubo" da palavra poética, da ignomínia e da difamação, da humilhação e do crime histórico. Palavra, língua e poesia - que "virá nos ajudar", "mudança de respiração", "aperto de mão" (expressões utilizadas por Celan nos textos poetológicos e cartas), ou "falso chamado" (kafkiano, do "Médico rural")? Palavra silenciada que é, diz o poeta, uma contrapalavra, que está sempre contra as palavras prostituídas pelos ouvidos dos carrascos (do poema “Argumentum e Silentio"). Mostram-se os dois aspectos da escritura (em especial no âmbito do trauma): aquele que restaura, da língua que torna possível a articulação; e o disruptivo, para o qual a única maneira de deter a escritura e a revivescência do terrível parece ser a morte. A dor das e nas palavras (que são sem exterior): é somente nelas e através delas que se pode restaurar o que fora fraturado, mas elas não oferecem garantias àquele que realiza tal imersão. $\mathrm{O}$ uso das palavras é feito, na poesia, para se proteger daquilo que advém senão das mesmas, metonimicamente contíguas à catástrofe.

\section{ABSTRACT}

The aporia between trauma and representation, put on by Celanian poetry, is often set against Adornian "dictum" on the impossibility of lyric after Auschwitz. In the present work, we intend to discuss this aporia starting from the grounds of Celan's legacy. A path out of the impasse is glimpsed through an "ethic of representation", which neither repeats obscenely the trauma nor keeps it quiet, but incorporates silence. Thus, Celan's 
poetic quotes the event, bringing it metonymically as a Proustian madeleine. It reveals as an indexical lyric that, as a scar or ruin, is linked to memory.

\section{KEYWORDS}

Poetry, Paul Celan, unsayable, catastrophe

\section{REFERÊNCIAS}

ADORNO, Theodor. Crítica cultural e sociedade. In: . Prismas. Trad. Augustin Wernet e Jorge Mattos Brito de Almeida. São Paulo: Ática, 1998. p. 7-26.

ADORNO, Theodor. Teoria estética. Trad. Artur Mourão. Lisboa: Edições 70, 1982.

BARRENTO, João. Paul Celan: o Verbo e a Morte. In: CELAN, Paul. Sete rosas mais tarde: antologia poética. Seleção, tradução e introdução de João Barrento e Y. K. Centeno. Lisboa: Cotovia, 1996.

BRECHT, Bertolt. Poemas e canções. Trad. Geir Campos. Rio de Janeiro: Civilização Brasileira, 1966.

CELAN, Paul. A morte é uma flor: poemas do espólio. Trad. João Barrento. Lisboa: Cotovia, 1998.

CELAN, Paul. Die Gedichte: Kommentierte Gesamtausgabe. Frankfurt a. M.: Suhrkamp, 2005.

CELAN, Paul. Sete rosas mais tarde: antologia poética. Seleção, tradução e introdução de João Barrento e Y. K. Centeno. Lisboa: Cotovia, 1996.

GAGNEBIN, Jeanne Marie. Após Auschwitz. In: . Lembrar escrever esquecer. São Paulo: Ed. 34, 2006.

SELIGMANN-SILVA, Márcio. O local da diferença. São Paulo: Ed. 34, 2006. 